\title{
A BRIEF EARLY HISTORY OF PLANT SCIENCE IN ST. LOUIS AND THE PARTNERSHIP BETWEEN WASHINGTON UNIVERSITY AND THE MISSOURI BOTANICAL GARDEN $^{1}$
}

\author{
Ralph S. Quatrano ${ }^{2 *}$ and Audrey S. Metcalf ${ }^{3}$
}

\begin{abstract}
Since the founding of the Missouri Botanical Garden (MBG) in 1859, the emphasis on research and the distribution of research findings in botany has been, and will remain, one of the central components of the garden's mission. Likewise, Washington University in St. Louis (WUSTL), the MBG's partner in graduate programs since 1885, has had a continuous and similarly strong emphasis on research and the dissemination of research findings in plant science through publications. Since the beginning of this partnership, the ongoing extension of common research themes has been critical, through the early focus on traditional botanical studies (1885-1930) at the MBG, the move toward a focus on physiology and the emerging field of ecology (1930-1960), and eventually the shift to the study of biochemistry, molecular biology, and genomic studies in plant science (1960-present), primarily at WUSTL. For more than 135 years (1885-2020), this St. Louis-based collaboration has had a prominent place in the region's rich history in plant science. In recent years, collaboration with and contributions from other St. Louis-area degreegranting institutions in the field (such as Saint Louis University [SLU] and the University of Missouri-St. Louis [UMSL]) have steadily increased. Couple this with the addition of the Donald Danforth Plant Science Center (Danforth Center) in 2000, which, like the MBG, has undertaken research and training in plant science, and you now have impressive depth and diversity within St. Louis's plant science offerings. As a result, both organizations train students and carry out peer-reviewed research funded by the same agencies (i.e., National Institutes of Health, National Science Foundation, U.S. Department of Agriculture) as the region's degree-granting institutions. Every year, a significant number of master's degree and Ph.D. graduates in this consortium comprise an impressive pool of talent available for postdoctoral training, research, and teaching positions, as well as employment in government entities and private and public life science corporations. To this end, St. Louis has one of the largest concentrations of plant science Ph.D.'s in the world (with more than 1,000 such individuals residing in the region [BioSTL, 2018]), as well as a broad diversity of disciplines represented. In addition, the faculties at both the Danforth Center and MBG frequently serve as adjunct members of university departments and as advisors to graduate students, and greatly increase the breadth of topics offered in the St. Louis plant science community, particularly in areas not directly supported by the universities. Both organizations contribute to an increasingly important part of this ecosystem. Below is a short history of the relationship between the MBG and WUSTL, and how this collaboration, primarily through graduate research education, has been foundational for the St. Louis area's impressive plant science ecosystem. This is not a detailed review of the science generated by these organizations, but rather an account of the initial events and leaders that led to the region becoming the present-day hub for plant science.
\end{abstract}

Key words: Botany, Division of Biology \& Biomedical Sciences, graduate, Henry Shaw, Henry Shaw School of Botany, Missouri Botanical Garden, Ph.D., plant science, Washington University in St. Louis.

In promoting the strengths of the St. Louis plant science community, the long history of and contributions by universities and research institutions in the region supporting graduate education are often overlooked by

\footnotetext{
${ }^{1}$ We would like to thank the following individuals for their advice and recommendations throughout the completion of this narrative: Dr. Peter Wyse Jackson, Dr. Peter H. Raven, Dr. James S. Miller, and Dr. Peter C. Hoch (Missouri Botanical Garden); Sam Fiorello (Cortex Innovation Community); Dr. Edward S. Macias (Office of the Provost and Department of Chemistry, Washington University in St. Louis); Dr. Garland E. Allen (Department of Biology, Washington University in St. Louis); and Dr. P. Roy Vagelos (retired, Merck \& Co., Inc.). We also extend our gratitude to the following individuals for their assistance in providing graduate student records, data, and research materials: Tom Bander, Allison Brown, and Elizabeth McNulty (Donald Danforth Plant Science Center); Andrew Colligan (Missouri Botanical Garden); Dr. Robyn S. Klein and Andrew Richards (Division of Biology \& Biomedical Sciences, Washington University in St. Louis); Associate Vice Chancellor Michael S. Kinch (Washington University in St. Louis); Dean William F. Tate (Graduate School of Arts \& Sciences, Washington University in St. Louis); University Registrar Sue Hosack, Associate Dean Angela Wilson, Steven Rakel, and Tara Sandretto (Office of the Registrar at Washington University in St. Louis); and Miranda Rectenwald (University Archives at Washington University Libraries).

${ }^{2}$ Spencer T. Olin Emeritus Professor of Biology and Emeritus Dean, Department of Biology, Washington University in St. Louis, St. Louis, Missouri 63130, U.S.A.

${ }^{3}$ Department of Biology and University Advancement, Washington University in St. Louis, St. Louis, Missouri 63130, U.S.A.

* Author for correspondence: rsq@wustl.edu.
} 
grant-making organizations, foundations, and corporations. We hope that this narrative, as well as any further additions and modifications to this historical account, will be helpful in better informing the audience on how academia and the research community were, and will continue to be, foundational with regard to St. Louis's ongoing plant science initiatives.

Since 1885, graduate programs in plant science have had a prominent place in St. Louis history, primarily at Washington University in St. Louis (WUSTL) through its partnership with the Missouri Botanical Garden (MBG). More recent contributions from the Donald Danforth Plant Science Center (Danforth Center) and other degree-granting institutions in the St. Louis region, including Saint Louis University (SLU) and the University of Missouri-St. Louis (UMSL), have also enhanced plant science in the region. Every year, a significant number of master's degree and Ph.D. graduates comprise an impressive pool of talent available for postdoctoral training, research, and teaching positions, as well as employment in government entities and private and public life science corporations. To this end, St. Louis has one of the largest concentrations of plant science Ph.D.'s in the world, with more than 1,000 such individuals residing in the region (BioSTL, 2018).

This short history of plant science in St. Louis covers some key individuals and events from 1885 to the 1970 s and is just the start of what could be a more extensive review of this topic. We would like to think of this narrative as the beginning of a more comprehensive presentation of the history and opportunities for future growth in St. Louis's plant science ecosystem.

\section{EARLY HisTORY}

One can trace the history of plant science in the St. Louis region back to its early days as a settlement and the founding of the city itself. In 1764, André Michaux, a noted French botanist and explorer, traveled to the East Coast of the United States for the first time in 1785, engaging in many plant collecting trips along the coast and developing botanical gardens in Bergen, New Jersey, and Charleston, South Carolina. Michaux was one of the earliest explorers to travel westward, making it as far as the Mississippi River, and published records of his plant collections found near and around St. Louis. (We know he visited Kaskaskia and Cahokia in southern Illinois, and some collections were from the nearby Missouri River [McKelvey, 1955: 107-108].) In the 1880s, after nearly a century of similar collections by Michaux and others, came an increasing emergence of botanical gardens in the United Kingdom, mainland Europe, and the United States. (Detailed records and discussions of early explorers, sites, and botanical activities in the St. Louis area can be found in publica- tions by P. Spaulding [1909].) The St. Louis region was no exception to the rise of these horticultural centers, and it was only a short time later that St. Louis would become home to the MBG.

Henry Shaw, an astute businessman, came to St. Louis in 1819 from his native England. With an initial capital investment from his uncle and a supply chain through New Orleans up the Mississippi River, Shaw made his fortune selling Sheffield-manufactured hardware and cutlery. In 1840, he retired from active business at the age of 40 and, while visiting the estate of the Duke of Devonshire in Chatsworth, England, was inspired to establish a botanical garden in St. Louis. In pursuit of this new project, an increasing interest in plant collections, and having invested wisely in land acquisition in the St. Louis region, in 1851, he wrote about his plans to W. J. Hooker (founding director of the Royal Botanic Gardens at Kew in Richmond, England), who suggested that Shaw reach out to Dr. Asa Gray (Harvard Professor and leading American botanist). Gray, in turn, directed Shaw to Dr. George Engelmann (a physician and noted botanist in St. Louis), who became Shaw's close scientific advisor and friend. It was with the guidance received from these men that, in 1859, Shaw founded the MBG.

Since the late 19th century, a strong link has existed between WUSTL and the garden, starting with appointing the chancellor of the university to an ex-officio seat on the MBG board. In addition, Shaw had also agreed to endow WUSTL's first science department—a school of botany. Sylvester Waterhouse, a classics professor at WUSTL, can be said to have helped start the conversations for the establishment of a school for botanical studies when he wrote to Shaw to suggest that the endowment for a professorship of botany and the MBG be under the supervision of the university (Washington University in St. Louis, 2010). Shaw initially declined, but later came to see the value instead of creating a school and endowing a professorship. In 1885, the Henry Shaw School of Botany was established as a department within WUSTL, to encourage botanical research at the start of this collaboration. In addition, as part of the transaction, a professorship was endowed in honor of Engelmann.

Additional individuals were clearly influential in defining the mission of the Shaw School of Botany and include Gray and Engelmann. Their impact was apparent from the school's beginnings, as it was the only one at WUSTL founded with a charge to promote research. From this early stage, research was the primary focus. The deed conveying the Shaw School of Botany's endowment to the university specified that the net income was to be used for "defraying the necessary ... expenses of those engaged in botanical instruction and research as well as for the maintenance of the botanical laboratories 
used for investigation" (Shaw, 1890a: 57). The endowment for the school was furnished by a building at Laclede's Landing in St. Louis owned by Shaw and made with the stipulation that if the income fell below $\$ 3,500$ annually, the Board of Trustees would be obliged to make up the difference. Shaw's will repeated this stipulation and added another condition even more emphatic in intention, stating, "Scientific investigations in Botany . . . are to be promoted not less than instruction to pupils. .." (Shaw, 1890b: 37).

The Shaw School of Botany was temporarily housed on property deeded to the university by Shaw. The value of the lot, located at 1724 Washington Avenue in St. Louis, was estimated to be $\$ 1.25$ million at the time (Spaulding, 1909: 247), and served for many years as the main site of undergraduate instruction in botany, while graduate work was primarily carried out at the MBG in the museum building and later in the administration building. In addition, in accordance with Shaw's deed to WUSTL, which stated the school was to be "placed under the special care and direction of an Advisory Committee" (Shaw, 1890a: 56), such a committee was established. The initial members included Shaw, William G. Eliot, Jr. (chancellor of WUSTL), Gray, Judge John H. Lightner (St. Louis County Executive 1859-1863), and Engelmann. It is important to note that Engelmann's appointment occurred posthumously and was carried out by Professor William Trelease (noted plant taxonomist, professor of botany, and future director of the MBG).

At the same time of the Shaw School of Botany's establishment, Shaw also endowed a professorship named for Engelmann, who had immigrated to Belleville, Illinois, from Germany in 1833, and later joined the faculty at WUSTL in 1856, where he taught until his death in 1884. He founded the Western Academy of Natural Sciences in 1836, which was devoted to the "intellectual improvement of its members and a general diffusion of scientific information throughout the state of Missouri" (Missouri General Assembly Committee on Legislative Research, 1836: 142). With the help of others, Engelmann also established the Academy of Science of St. Louis in 1856 and served as its first president (he would go on to be elected president a total of 16 times). The new academy reinvigorated interest in science and led to the publication of an internationally recognized journal of scientific research, Transactions of the Academy of Science of St. Louis.

The inaugural George Engelmann Professor of Botany at WUSTL, as stipulated by Shaw before his death, was held by Trelease. Here, Gray's influence is evident yet again, as he was deeply involved in the recommendation and recruitment of Trelease, a student of his, to fill the professorship. He put Trelease's qualifications before Shaw and the chancellor of WUSTL (Eliot) and allayed Shaw's concern that Trelease was too interested in research and not the "work of elementary and popular instruction” (Morrow, 1996: 97).

Gray's persistence can be attributed to his efforts to ensure that Shaw's provision made for research had a champion. Trelease, who was initially drawn to St. Louis by the MBG, was strongly committed to graduate education and began an active graduate program within the Shaw School of Botany shortly after he arrived at WUSTL in 1885. Unlike older members of the faculty, Trelease's pursuit of science began during his undergraduate years at Cornell University and continued throughout his graduate studies at Harvard, where he learned that the "laboratory, rather than fieldwork or lectures, was the principal agent for advancing science" (Morrow, 1996: 97). In addition, Trelease stated, "one of the most important features of the work of a university ... [was] properly held to be original study ..." (Trelease, 1890: 86). He itemized a list of research projects, both completed and in progress, that is impressive even by late 20 th-century standards $(\mathrm{Ru}-$ dolph, 1991: 7). In 1889, following the death of Shaw, Trelease became the first director of the MBG. Like Trelease, every subsequent holder of the Engelmann Professorship at WUSTL has also been the director of the MBG, including the current holder, Dr. Peter Wyse Jackson.

The appointment of Trelease as head of the Shaw School of Botany at its establishment, and his subsequent appointment as the inaugural director of the MBG, began an academic era that lasted throughout his 27- and 29-year tenures at the MBG and WUSTL, respectively. One can argue that this was the beginning of a new period in academia at WUSTL, which initiated generations of academically trained scientists.

\section{Early Graduate Programs: A Continued Focus ON RESEARCH}

In 1885, WUSTL awarded its first non-honorary doctorate, a Ph.D. in botany, to Dr. Anna Isabel Mulford. A graduate student of Professor William Trelease, Mulford's handwritten dissertation (now located in the university archives at WUSTL) examined the genus Agave L. in the United States and resulted in a definitive account of the genus. She was later honored for her pioneering botanical research with several new species named for her, including Astragalus mulfordiae M. E. Jones (Mulford's milkvetch). Another early student, Dr. Hermann von Schrenk, received a doctorate in plant pathology from WUSTL and became the first federal forest pathologist in the United States, while also employed by the Henry Shaw School of Botany and the MBG as an instructor in plant pathology. In addition, at the World's Fair held in St. Louis in 1904, von Schrenk 
introduced the technique of impregnating railroad ties with creosote, which quadruples their useful life.

In the early 20 th century, a recovery in the financial fortunes of the MBG and a gift by Rufus L. Lackland, the long-serving president of the former Boatmen's Bancshares, Inc. (now a part of Bank of America Corporation) and chair of the garden's board, enabled WUSTL to expand research and training, something Trelease did not hesitate to act on. During Trelease's time as director of the MBG, he was also faced with the task of rejuvenating the garden grounds, which Shaw had let gradually decline for three decades. In taking on what would become yet another successful project, however, Trelease was inevitably faced with growing tensions around his many achievements, and the trustees of the MBG concluded that it was time for a change in leadership. In 1909, the university's chancellor, David F. Houston, and board president, Robert S. Brookings, prevailed upon the trustees of the MBG to finance the appointment of Dr. George T. Moore, head botanist for the Marine Biological Laboratory in Woods Hole, Massachusetts, as a professor of plant physiology and applied botany and to replace Trelease as director of the garden. Following the board's approval, Moore accepted the position and joined the MBG in 1912. That same year, Moore enlisted Dr. Benjamin T. Duggar, former chair of plant physiology at Cornell University, to take over his staff position at the Shaw School of Botany, which increased the school's strength in plant physiology. Over the next several decades, through close interaction and cooperation with the MBG, the Shaw School of Botany "quickly re-established itself as one of the foremost research centers in the country" (Morrow, 1996: 191).

In 1926, the Shaw School of Botany and the Department of Zoology at WUSTL moved into a more permanent site in Charles Rebstock Hall, funded by Charles Rebstock, the owner of a large liquor company and member of the university's board. Rebstock's gift (totaling $\$ 1$ million) provided $\$ 300,000$ for a building to house both the Shaw School of Botany and Department of Zoology, along with a $\$ 700,000$ endowment for building maintenance (O'Connor, 2003: 142). Around the same time, the Charles Rebstock Professorship in Biology was established. Rebstock Hall continues to house part of the Department of Biology today, including many plant biologists and the office of the chairman.

In 1950, Professor Henry N. Andrews, Jr. was named Dean of the Shaw School of Botany. At the same time as this appointment, however, because the school "... had only a negligible endowment to share in the college's [Arts \& Sciences] budgeted funds ..." (Faherty, 1989: 135), WUSTL began to list the Shaw School of Botany as the Department of Botany within the College of Liberal Arts under the Graduate School of Arts \&
Sciences (starting with its 1951-1952 catalogue). The university also began listing the College of Liberal Arts as the grantor of degrees in botany. In 1953, John Lehmann, an MBG trustee, became acting director and chair of the board for the garden and, in 1954, the MBG selected its next director, Dr. Edgar Anderson, who had been a member of the Shaw School of Botany's staff since 1926. He was a brilliant geneticist and an important instructor at WUSTL for the general public.

Anderson received his Doctor of Science in agricultural genetics from the Bussey Institution at Harvard University in 1922, where he worked on the genetics of self-incompatibility. Following graduation, Anderson accepted an invitation to join the MBG as director of the Henry Shaw School of Gardening and geneticist, positions he would hold for nine years. He also joined the faculty of the Shaw School of Botany at WUSTL, where he quickly earned a tenured associate professorship. During these first nine years, Anderson developed innovative research using very quantitative approaches in "observing and recording variation in natural populations that were entirely foreign to the taxonomists of that period" (Stebbins, 1978: 5). In 1929, he received a National Research Fellowship for study at the John Innes Institution in England, where he was guided by several world-renowned scientists in genetics, statistics, and cytology, such as Professor J. B. S. Haldane, Sir Ronald A. Fisher, and Dr. C. D. Darlington. In 1931, Anderson left the MBG, returning to Harvard as an arborist at the Arnold Arboretum, where his research would contribute to the concept of introgression. He returned to St. Louis and the MBG as a geneticist in 1935 and, in 1937, was named the George Engelmann Professor of Botany at WUSTL.

Like many, before and after his time, Anderson continued the tradition of revolutionary research of the MBG and WUSTL faculties. The recipient of many prestigious honors and awards, including election to the National Academy of Sciences, the Order of the Yugoslavian Crown, and the prestigious Darwin-Wallace Medal of the Linnean Society of London, Anderson brought great visibility to the garden and its close association with the university. In the National Academy of Sciences' biographical memoir of Anderson, G. Ledyard Stebbins wrote that "Edgar Anderson left an indelible impression on plant science of the twentieth century. His entire life revolved around his love of plants - wild and domestic in nature and the gardenand his eagerness inspired student and lay alike with a similar admiration for the love of the plant world" (Stebbins, 1978: 3).

While Anderson spent the remainder of his career at the MBG, his tenure as director was short-lived-he resigned after only two years, accepting the appointment of curator of useful plants at the garden and ulti- 
mately a return to research and teaching. After Anderson's resignation, Dr. Hugh Cutler, assistant director of the MBG, was named acting director, and served in this role until 1958, when Dr. Frits Went, a highly regarded expert from the California Institute of Technology on plant hormones and environmental influences on plant growth, was appointed. Went oversaw construction of the Climatron, the innovative geodesic-domed greenhouse at the MBG, but served as director only until 1963. Henry Hitchcock, president of the garden's board, went on to serve as acting director until 1965, when the MBG selected its next leader, well-known physicist Dr. David Gates. (For more information about all directors of the MBG, see A Gift to Glory In: The First Hundred Years of the Missouri Botanical Garden (1859-1959) by W. B. Faherty [1989].)

In 1947, Dr. Barry Commoner joined the faculty at WUSTL as a professor of plant physiology and environmental studies. Called "a founder of modern ecology and one of its most provocative thinkers and mobilizers in making environmentalism a people's political cause" by The New York Times (Lewis, 2 Oct. 2012: A1), Commoner's early research at the university focused on how plant viruses affect genetic material. This research, in turn, led to discoveries on how to detect and fight human disease at the genetic level. He would go on to help establish the St. Louis Committee for Nuclear Information in 1958 and served as chair of the Department of Botany at WUSTL from 1965 to 1969 (when the department merged with the Department of Zoology). In addition, in 1966, Commoner founded the Center for the Biology of Natural Systems in St. Louis to "study the effects of man on the environment" (Pettingell, 1977: 2). However, in 1981, following a failed presidential campaign, Commoner moved his center to Queens College in New York City.

As was previously mentioned, by 1951, in consultation with the MBG, WUSTL had begun to refer to the Shaw School of Botany as the Department of Botany. This was due in part to the decreasing value of the original endowment and in recognition of the rapid postwar growth and professionalization of the sciences. Staff continued to hold joint appointments at the MBG and WUSTL, a revised plant science curriculum for undergraduates was developed, and graduate students continued to pursue research at both the MBG and WUSTL. In 1969, WUSTL's Departments of Botany and Zoology merged to create the Department of Biology within the College of Liberal Arts (Navis, 2007).

Despite the name change, it is plausible to say that the Shaw School of Botany "secured the bridgehead for graduate education in the university" (Morrow, 1996: 93-99). While WUSTL's board authorized the granting of Ph.D. degrees in 1881, the arrival of the university's first George Engelmann Professor of Botany and the in-
Table 1. Plant science graduate degree totals from 1895 to 2018. Approximate number of plant science graduate degrees awarded from 1895 to 2018. Numbers are split between Saint Louis University (SLU)/University of Missouri-St. Louis (UMSL) and Washington University in St. Louis (WUSTL) alumni.

\begin{tabular}{lccc}
\hline \hline & SLU/UMSL & WUSTL & Grand Totals \\
\hline M.A./M.S. & 54 & 273 & 327 \\
Ph.D. & 133 & 425 & 558 \\
& 187 & 698 & 885 \\
\hline
\end{tabular}

augural director of the MBG, Trelease, made it exceedingly more likely that the awarding of doctoral degrees would receive sustained support from both the university and the MBG. In 1895, WUSTL awarded its first Ph.D., and during the next 20 years, 19 of the 21 research doctorates conferred by the university were in botany. Little did WUSTL know that approximately 135 years later (1895-2018), the number of Ph.D.'s in plant science awarded by the university would total more than 425, with over 140 associated with the MBG. Furthermore, when coupled with master's degrees, the total number of graduate degrees granted would exceed 690, with more than 220 associated with the MBG (Tables 1 and 2).

\section{The Division of Biology and Biomedical Sciences}

In the late 1960 s and early $1970 \mathrm{~s}$, major changes in the structure of graduate training in the life sciences occurred at WUSTL. Several scientists began thinking about how the university might integrate all the different specialties offered in the life sciences since multiple departments across the university's campuses had curriculums featuring various components of the field. While some departments were primarily in Arts \& Sciences, such as the Departments of Biology and Chemistry, others were housed at the School of Medicine, including, but not limited to, the Departments of Bio-

Table 2. Missouri Botanical Garden-associated plant science graduate degree totals (1895-2018). Approximate number of individuals who received graduate degrees in plant science from 1895 to 2018 who were associated with the Missouri Botanical Garden in some capacity during their studies. Numbers are split between Saint Louis University (SLU)/University of Missouri-St. Louis (UMSL) and Washington University in St. Louis (WUSTL) alumni.

\begin{tabular}{lccc}
\hline \hline & SLU/UMSL & WUSTL & Grand Totals \\
\hline M.A./M.S. & 50 & 142 & 192 \\
Ph.D. & 58 & 220 & 278 \\
& 108 & 362 & 470 \\
\hline
\end{tabular}


chemistry, Genetics, Immunology, and Microbiology. Many faculty members in these pre- and non-clinical departments shared common interests and specialties with colleagues across different disciplines, departments, and schools but, for the most part, were not housed within the same buildings or campus. These separations resulted in WUSTL's expertise in the life sciences being very diverse, diffuse, and extremely scattered geographically. Thus, the idea of grouping faculty members according to research interests was proposed, allowing the university to better capture its strength in the life sciences.

One of the leading figures in this restructuring was Dr. P. Roy Vagelos (former chair and professor of biological chemistry in the School of Medicine at WUSTL). In the early 1970s, Vagelos met with WUSTL Chancellor William H. Danforth to discuss his idea of a multidisciplinary doctoral program in biological sciences. Danforth proceeded to initiate conversations with other members of the life science community (including members of the plant science faculty) and found great enthusiasm for the potential alignment. Considering such positive feedback, Danforth gave Vagelos the seed money to conduct a pilot study at the university, which initially led to a combined M.D./Ph.D. program at the School of Medicine. The program provided students with the opportunity to both conduct research with and receive hands-on training from world-class physicians and scientists. This demonstration exemplified how those across many different disciplines could work together under one administrative unit.

In 1973, Vagelos's pilot study ultimately resulted in the formation of the Division of Biology \& Biomedical Sciences (DBBS), a groundbreaking and quickly emulated model for a multidisciplinary doctoral division built on establishing new programs spanning two schools. Faculty from the School of Medicine's pre- and nonclinical departments (Anatomy, Biochemistry, Genetics, Immunology, Microbiology, Pathology, and Physiology), and Arts \& Sciences' departments (Biology and Chemistry) established Ph.D. programs in Biochemistry and Biophysics, Evolution (now Evolution, Ecology, and Population Biology), Genetics, Immunology, Microbiology, and Plant Biology (now Plant and Microbial Biosciences). Each unit was comprised of faculty members with common interests from a mixture of former departments and, at its start, DBBS encompassed nearly 150 of WUSTL's instructors, researchers, and scientists. Simultaneously, these former departments ceased operating any individual graduate programs - a bold move by the university that would go on to have a revolutionizing impact on how biological science is taught at the graduate level. The one exception was the Department of Biology in Arts \& Sciences, which was left intact primarily due to its major commitment to the undergraduate teaching of all biology topics in introductory courses, including plant science.

DBBS was structured as a division independent of any one school or department at WUSTL, with operations overseen by an executive committee composed of the chairs of participating departments. This committee, in turn, reported to both the Dean of the School of Medicine and the Dean of Arts \& Sciences. In terms of supporting DBBS from a monetary perspective, financing initially came from both schools in the form of endowments and annual operating funds. This support was a critical component of the program's success, as its graduate students received tuition assistance from the endowments rather than grants, allowing faculty to use grant funding received directly for research.

While Vagelos oversaw the establishment of DBBS and served as its inaugural director, he left WUSTL in 1975 to join the executive team at Merck \& Co., Inc. After Vagelos's departure, the university named Luis Glaser, Ph.D. chair of the Department of Biological Chemistry and director of DBBS. In a spring 1995 article from Washington University Magazine and Alumni News, Vagelos reflected on the dramatic impact the effort has had on biological sciences in academia, stating "The initiation of the Division of Biology and Biomedical Sciences ... gave [WUSTL] the ability to bring together ... faculty-both basic and scientific-from two campuses separated by a park. Chancellor Danforth and the university put together a program that may be the strongest in the country. It has revolutionized the teaching of graduate students and has dramatically enhanced the teaching of science. It allowed medical school faculty to teach at the undergraduate school" (Washington University in St. Louis, 1995).

As the name indicates, the programs offered in DBBS focus on the study of basic biological and biomedical sciences, with the primary concentration on obtaining a Ph.D. training. Although DBBS emphasized medically related fields at its onset, plant science was one of the initial fields of study the division offered. More recently, due to the changing interests and caliber of students and expansion of overlapping disciplines, the two programs that comprise the department's plant science studies have been renamed Evolution, Ecology, and Population Biology (EEPB) and Plant and Microbial Biosciences (PMB). These two programmatic offerings are also particularly relevant to the integration of outstanding plant science faculty members, both in academia and from the MBG and Danforth Center. In fact, it was, in part, senior faculty hires to whom the MBG and WUSTL looked in order to maintain the close connection between the two organizations and uphold a strong presence of plant science at the university.

Essential to the significant and exciting changes in the life sciences during the 1970s, 1980s, and 1990s 
was the enduring strength of plant science education at WUSTL and the partnership between the MBG and university. Critically important were the aforementioned senior faculty hires, which notably included three plant scientists with major leadership roles-Drs. Peter H. Raven, Barbara A. Schaal, and Ralph S. Quatrano.

In 1971, Raven was named director of the MBG and the George Engelmann Professor of Botany at WUSTL. He brought both a dedication to and research program for biodiversity and plant conservation and has been a passionate advocate for these topics in public policy forums. During his four decades overseeing the garden, Raven maintained a strong commitment to research and an equally robust partnership with WUSTL. (He significantly grew the scientific [Ph.D.] staff [from five in 1971 to more than 60] and led the MBG's ascent to one of the most active botanical research institutions in the world.) In 1980, Schaal joined the MBG as a research associate and WUSTL as a faculty member in the Department of Biology and DBBS, bringing additional expertise in plant evolutionary biology. (Schaal's significant contributions eventually led to her becoming WUSTL's Chair of the Department of Biology from 1993 to 1997.) Quatrano, a well-known plant cell and developmental biologist from the University of North Carolina at Chapel Hill, came to St. Louis in 1998 as a professor in and chair of the Department of Biology at WUSTL, a position he held until 2008. In addition, from 2005 to 2007, Quatrano served as director of DBBS. These three plant scientists were instrumental not only in sustaining the relationship between the MBG and WUSTL, but also in helping ensure that plant science maintained a strong presence in both the Department of Biology and DBBS.

The faculty integration into the EEPB program served as a conduit and model for academics at the MBG (e.g., adjunct faculty at the garden could easily become faculty members of EEPB and/or PMB). Furthermore, integration of existing faculty members and new recruits to St. Louis's current and future plant science institutions was championed by Raven, Schaal, and later by Quatrano. Well-established members of the plant science community, many of whom had notable research
Table 3. Department of Biology and Division of Biology \& Biomedical Sciences Faculty (1975-2000). Members of the plant science community who retained their roles or joined Washington University in St. Louis as new faculty members between 1975 and 2000. List is split between faculty from the Missouri Botanical Garden and Washington University in St. Louis.

\begin{tabular}{ll}
\hline \hline Missouri Botanical Garden & \multicolumn{1}{c}{$\begin{array}{c}\text { Washington University } \\
\text { in St. Louis }\end{array}$} \\
\hline Thomas Croat, Ph.D. & $\begin{array}{l}\text { Roger N. Beachy, Ph.D. } \\
\text { William G. D'Arcy, Ph.D. }\end{array}$ \\
$\begin{array}{l}\text { Mary-Dell Chilton, Ph.D. } \\
\text { Gerrit Davidse, Ph.D. }\end{array}$ & Ursula W. Goodenough, Ph.D. \\
Alwyn H. Gentry, Ph.D. & Tuan-Hua (David) Ho, Ph.D. \\
Peter C. Hoch, Ph.D. & David L. Kirk, Ph.D. \\
Robert Magill, Ph.D. & Barbara Kunkel, Ph.D. \\
Peter H. Raven, Ph.D. & Walter H. Lewis, Ph.D. \\
P. Mick Richardson, Ph.D. & Himadri Pakrasi, Ph.D. \\
Jan Salick, Ph.D. & Barbara G. Pickard, Ph.D. \\
& Craig Pikaard, Ph.D. \\
& Ralph S. Quatrano, Ph.D. \\
& Peter H. Raven, Ph.D. \\
& Eric J. Richards, Ph.D. \\
& Barbara A. Schaal, Ph.D. \\
& Owen J. Sexton, Ph.D. \\
& Joseph E. Varner, Ph.D. \\
& Virginia Walbot, Ph.D. \\
\hline
\end{tabular}

funding, retained their roles or joined the university as new faculty members in the Department of Biology and DBBS between 1975 and 2000. (See Table 3 for a list of these faculty members.) They also maintained their roles in undergraduate instruction, but for graduate student affiliations were appointed as members of DBBS programs, most likely in EEPB and/or PMB. (It should be noted that, while most of the faculty members in the DBBS plant science program were from the Department of Biology, a few from the Department of Chemistry and the School of Medicine also contributed.) Since its inception in 1973, DBBS programs have granted more than 145 Ph.D.'s from its plant science programs, with approximately 49 in EEPB and 97 in PMB (Table 4). The model used in DBBS allowed for the inclusion of those from fields related to plant science in this inter-

Table 4. Washington University in St. Louis Division of Biology \& Biomedical Sciences Plant Science Ph.D. Totals (19782018). Approximate number of Washington University in St. Louis's Division of Biology \& Biomedical Sciences alumni with degrees in plant science awarded from 1978 to 2018. Numbers are split between those who were and were not associated with the Missouri Botanical Garden (MBG) in some capacity during their studies.

\begin{tabular}{lccr}
\hline \hline & MBG-associated & Non-MBG-associated & Grand Totals \\
\hline Evolution, Ecology, and Plant Biology & 49 & 0 & 49 \\
Plant and Microbial Biosciences & 0 & 7 & 7 \\
Plant Biology & 3 & 87 & 90 \\
& 52 & 94 & 146 \\
\hline
\end{tabular}


disciplinary program. In addition, starting in the 1970s, other universities in the St. Louis region began offering graduate degrees in plant science and plant biology, including SLU and UMSL. From 1970 to the present, SLU and UMSL have awarded approximately 187 (Table 1) plant science and plant biology graduate degrees, both master's and Ph.D.'s.

These numerous programs and institutions, from degree-granting organizations in academia to worldrenowned plant science research establishments, clearly demonstrate that plant science graduate programs in the St. Louis region continue to grow and flourish. While only a few of these institutions, primarily the MBG and WUSTL, were responsible for graduate training in plant science prior to 1950, one can assume that with the increasing contributions of SLU and added presence of UMSL and the Danforth Center, among others, the region's great capacity for such opportunities will continue to grow in perpetuity.

\section{SuMMARY}

This short narrative outlines a brief history of plant science programs in St. Louis, starting in 1885 with the Henry Shaw School of Botany at WUSTL, to the establishment of DBBS in the 1970s. For approximately the first 75 years of this period, almost all the activity in plant science revolved around the partnership between the MBG and WUSTL. (We have extensive records of the degrees, focus areas, and names of students who graduated during this period.) Starting in the early 1950s, SLU and UMSL joined WUSTL in awarding master's degrees and Ph.D.'s in plant science. In addition, since the early 2000 s, mentors, facilities, and programs at the Danforth Center have played, and continue to play, an increasingly important role for all Ph.D. programs.

It is our hope that more extensive additions will be made examining this history, as plant science continues to serve as a defining feature of the St. Louis region both academically and economically.

Accompaniments to the narrative above will help highlight the tremendous advances from the 1980s to the present. For example, the significant increase in the number of new companies that have been attracted to St. Louis (KWS Gateway Research Center), as well as the development and nourishment of many others (Benson Hill, Inc.), has been tremendous, and the expansion of the Danforth Center's faculty, facilities, and programming is impressive.

We feel that this short manuscript, and any expansions, can and should be used in conjunction with information developed by business (St. Louis Regional
Chamber) and community groups (BioSTL) to promote St. Louis's plant science initiative. Having robust graduate programs already in place and a steady stream of plant science graduates will undoubtedly continue to prove beneficial in attracting additional support from grants, foundations, and corporations. As it stands today, St. Louis is poised for additional impact to the region in the years to come, but the plant science community must recognize, promote, and coordinate to expand its ecosystem in order to ensure its continued success.

\section{Literature Cited}

BioSTL. 2018. 39 North. <https://www.biostl.org/what-we-do /place>, accessed 2 February 2019.

Faherty, W. B. 1989. A Gift to Glory In: The First Hundred Years of the Missouri Botanical Garden (1859-1959). Harris \& Friedrich, Ocean Park, Washington.

Lewis, D. 2012. Saw an earth at risk and let the world know. New York Times, 2 Oct. 2012. <https://www.nytimes.com /2012/10/02/us/barry-commoner-dies-at-95.html>, accessed 23 November 2019.

McKelvey, S. D. 1955. Botanical Exploration of the TransMississippi West, 1790-1850. Arnold Arboretum of Harvard University, Jamaica Plain.

Missouri General Assembly Committee on Legislative Research. 1836. Laws of the State of Missouri Passed at the First Session of the Ninth General Assembly. Ninth Missouri General Assembly. Isaac N. Henry, Jefferson City.

Morrow, R. E. 1996. Washington University in St. Louis: A History. Missouri Historical Society Press, St. Louis.

Navis, A. R. 2007. Washington University in St. Louis. Embryo Project Encyclopedia. <http://embryo.asu.edu/handle /10776/1673>, accessed 10 December 2018.

O'Connor, C. 2003. Beginning a Great Work: Washington University in St. Louis, 1853-2003. Washington University in St. Louis, St. Louis.

Pettingell, S. 1977. Barry Commoner: Where science meets terrorism. Executive Intelligence Rev. 4(43): 2.

Rudolph, E. D. 1991. One hundred years of the Missouri Botanical Garden. Ann. Missouri Bot. Gard. 78(1): 1-18.

Shaw, H. 1890a. Deed from Henry Shaw to Washington University. Pp. 56-58 in Missouri Botanical Garden Annual Report. Missouri Botanical Garden Press, St. Louis.

Shaw, H. 1890b. The will of Henry Shaw, establishing the Missouri Botanical Garden. Pp. 29-55 in Missouri Botanical Garden Annual Report. Missouri Botanical Garden Press, St. Louis.

Spaulding, P. 1909. A biographical history of botany at St. Louis, Missouri, IV. Popular Sci. Monthly 74: 247.

Stebbins, G. L. 1978. Edgar Anderson, 1897-1969. Biogr. Mem. Natl. Acad. Sci. U.S.A. 49: 3-23.

Trelease, W. 1890. Report on the School of Botany. P. 86 in Missouri Botanical Garden Annual Report. Missouri Botanical Garden Press, St. Louis.

Washington University in St. Louis. 1995. The Danforth vision of Washington University: Teaching and learning. Washington University Magazine and Alumni News 65(1): 14.

Washington University in St. Louis. 2010. National honors for three WUSTL biologists. <https://source.wustl.edu/2010/04 /three-wustl-biologists-earn-national-honors/>, accessed 7 December 2018. 